\title{
THE STRUCTURE OF CODONOPSININE
}

S. F. Matkhalikova, V. M. Malikov, and S. Yu. Yunusov

Khimiya Prirodnykh Soedinenii, Vol. 5, No. 6, p. 607, 1969

UDC 547.944/945

Continuing an investigation of the epigeal part of Codonopsis clematidea (clematis asiabell) from the mother liquors from codonopsine (I), we have isolated a new base with the composition $\mathrm{C}_{13} \mathrm{H}_{19} \mathrm{O}_{3} \mathrm{~N}$, mol. wt. 237 (mass spectrometry), $\mathrm{mp} 169-170^{\circ} \mathrm{C}$ (methanol), $[\alpha]_{\mathrm{D}}^{20}-8.8^{\circ}$ (c 0.1 ; methanol), $\mathbf{R}_{f} 0.23$ [on a thin layer of silica gel-gypsum in ethyl acetate-methanol $(9: 1)$ system], and we have called it codonopsinine.

The IR spectrum of the alkaloid has absorption bands at $\left(\mathrm{cm}^{-1}\right): 812,705$ (disubstituted benzene nucleus) and 3375 (active hydrogen). UV spectrum, $\lambda_{2} \mathrm{C}_{2} \mathrm{H}_{5} \mathrm{OH}, \mathrm{m \mu}: 228,277$, and 284 (inflection) (log $\varepsilon$ 4.14, 3.22, and 3.14 , respectively). The IR and UV spectra of codonopsinine are similar to those for codonopsine.

The NMR spectrum of the base taken on a JNM-4H-100/100 MHz spectrometer in deuterochlor of orm show signals from the protons of a $\mathrm{N}-\mathrm{CH}_{3}$ group (singlet, $\tau, 7.92$ ), a $\mathrm{CH}-\mathrm{CH}_{3}$ group (doublet, $\tau 8.85$ ), and an $\mathrm{OCH}_{3}$ group (singlet, $\tau$ 6.46). A comparison of the NMR spectra of this base and of codonopsine showed that codonopsinine contains only one methoxyl group in the aromatic molety.

The mass-spectrometric fragmentation of codonopsinine is similar to that of codonopsine [2]. The spectrum has peaks of ions with $\mathrm{m} / \mathrm{e} 237\left(\mathrm{M}^{+}\right), 177,176$, and 162 , which differ from the corresponding peaks of codonopsine by 30 $\mathrm{m} / \mathrm{e}$.

The oxidation of codonopsinine with potassium permanganate in acetone yielded an acid with $\mathrm{mp} 110^{\circ} \mathrm{C}$, which was identified by a mixed-melting-point test as $\mathrm{m}$-methoxybenzoic acid.

On the basis of what has been said above, it is possible to propose for codonopsinine the structure 3,4 -dihydroxy5-(m-methoxyphenyl)-1, 2-dimethyl-pyrrolidine:

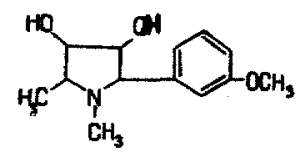

\section{REFERENCES}

1. S. F. Matkhalikova, V. M. Malikov, and S. Yu. Yunusov, KhPS [Chemistry of Natural Compounds], 5, 30, 1969.

2. S. F. Matkhalikova, V. M. Malikov, and S. Yu. Yunusov, KhPS [Chemistry of Natural Compounds], 5, 606, 1969 (in this issue.)

8 July 1969

Institute of the Chemistry of Plant Substances AS UzSSR 